\title{
Comunicado de Prensa: Alerta sobre una campaña publicitaria que promueve la vacunación contra el virus del papiloma humano (HPV)
}

Espacio cedido por el comité editorial de Evidencia, Actualización en la práctica ambulatoria a la Federación Argentina
de Medicina Familiar y General (FAMFyG).
En el próximo número se presentará una editorial sobre el tema tratando de poner en perspectiva esta controvertida
campaña.

La Federación Argentina de Medicina Familiar y General quiere comunicar a los profesionales del área de la salud su preocupación sobre una campaña publicitaria de la Liga Argentina de Lucha contra el Cáncer (LALCEC), en la cual se está exhortando a las mujeres a vacunarse para evitar el cáncer de cuello uterino (única palabra destacada) sin mencionar la prueba de Papanicolaou como recurso preventivo. De acuerdo a fuentes periodísticas $^{1,2}$ no desmentidas, dicha campaña pareciera haber sido financiada por la industria farmacéutica.

Cabe destacar que la vacuna contra el virus del papiloma humano (HPV) no ha sido incluida en el calendario oficial de vacunación.

Ante estos hechos la Federación Argentina de Medicina Familiar y General desea alertar a la población y manifestar que de acuerdo a las evidencias científicas y los principios de la ética profesional:

1- La realización periódica del test de Papanicolaou es la única medida que hasta el momento ha demostrado disminuir entre un 20 y un $60 \%$ la mortalidad por cáncer de cuello uterino ${ }^{3}$.

2- La vacuna contra el HPV ha demostrado ser eficaz para evitar lesiones relacionadas con el virus ${ }^{4}$ y solo en mujeres que no hayan iniciado relaciones sexuales, pero se desconoce su efecto en la incidencia y mortalidad por cáncer de cuello uterino y su protección a mediano y largo plazo.
3- La vacuna sólo cubriría un $65 \%$ de los HPV relacionados con las neoplasias de cuello uterino en Latinoamérica y el Caribe ${ }^{5}$.

4- La vacunación ha sido financiada (al menos parcialmente) por los Estados Nacionales ${ }^{6}$ en 15 países desarrollados, pero en países en vías de desarrollo como la Argentina esto resultaría extremadamente difícil de financiar y no debería constituir una prioridad sanitaria ${ }^{7}$.

5- Deberían realizarse en Argentina estudios de costo-efectividad antes de implementar estrategias preventivas masivas. En el caso del cáncer del cuello de útero, cualquier medida debería integrarse claramente con programas de detección temprana siendo el Papanicolaou la prueba de elección.

6- Es objetable desde la ética institucional ofrecer intervenciones preventivas de acceso inequitativo, con información distorsionada y a través de publicidades encubiertas.

Por último, la Federación Argentina de Medicina Familiar y General recomienda que aquellas mujeres que decidan recibir la vacuna deberán continuar realizándose periódicamente un test de Papanicolaou, dado que la vacuna, por lo que se sabe hasta la fecha, no garantiza una protección total contra el cáncer del cuello uterino

\footnotetext{
Referencias

1. Pedro Lipcovich. Vacuna, campaña y polémica. En: http://www.pagina12.com.ar/diario/sociedad/3-113945-2008-10-25.html (acceso 3/11/2008).

2. LA SALUD, ¿UN NEGOCIO? Escrito por: zoe el 28 Oct 2008. En: http://blogs.clarin.com/el-conventillo-de-info/2008/10/26/solo-mujeres- (acceso 3/11/2008).

3. U.S.Preventive Services Task Force (USPSTF) Screening for Cervical Cancer. Recommendations and Rationale.

http://www.ahrq.gov/clinic/3rduspstf/cervcan/cervcanrr.htm\#clinical (acceso 1/11/2008).

4. Rambout $\mathrm{L}$ y col. Prophylactic vaccination against human papillomavirus infection and disease in women: a systematic review of randomized controlled trials. CMA 2007;177:469-79.

5. Ciapponi A y col. Type-specific HPV prevalence in high grade lesions or cervical cancer in Latin America and the Caribbean: a systematic review of epidemiological studies. 24 th International Papillomavirus Conference and Clinical Workshop. -3 al 9 de Noviembre de 2007.

6. Koulova A y col. A brief report: Country recommendations on the inclusion of HPV vaccines in national immunization programmes among high-income countries, June 2006January 2008. Vaccine. 2008 Sep 18. [Epub ahead of print]

7. Goldie S y col. Cost-effectiveness of HPV 16, 18 vaccination in Brazil. Vaccine. 2007 Aug 14;25(33):6257-70. Epub 2007 Jun 15.
} 